Article

\title{
Developing Triploid Maples
}

\author{
Ryan N. Contreras * (1) and Tyler C. Hoskins \\ Department of Horticulture, Oregon State University, 4017 Agricultural and Life Sciences, \\ Corvallis, OR 97331, USA; tyler.hoskins@oregonstate.edu \\ * Correspondence: ryan.contreras@oregonstate.edu; Tel.: +541-737-5462
}

Received: 5 September 2020; Accepted: 19 October 2020; Published: 21 October 2020

check for updates

\begin{abstract}
Maples are common street and shade trees throughout the temperate zone. They are widely used for their wide range of ornamental traits and adaptability, particularly to urban settings. Unfortunately, some species such as Acer tataricum ssp. ginnala (Amur maple) and A. platanoides (Norway maple) have escaped cultivation to become pests or in some cases threaten native flora. However, these species remain economically important and are still asked for by name. To ameliorate potential future ecological damage from additional escapes, we have been breeding for sterile forms using ploidy manipulation and backcrossing to develop triploids. We began with a series of experiments to develop tetraploids of Amur, Norway, and trident (A. buergerianum) maples. Treatment of seedlings at the cotyledon or first true leaf stage was successful in inducing tetraploids of each species. Mortality, cytochimeras, and tetraploids varied among species. After identifying tetraploids, they were field planted alongside diploid cultivars and seedlings, which served as pollinizers in open-pollination. Seedlings derived from open-pollinated tetraploids were generally found to be a high percentage triploids. Thus far, no Norway or trident maple triploids have flowered but after three years we observed five, 22, and 22 Amur maple triploids flowering over three respective years with no seedlings recovered to date. Further evaluation is required but our findings are encouraging that the triploids we have developed thus far will be sterile and provide new cultivars for nursery growers and land managers.
\end{abstract}

Keywords: Acer buergerianum; Acer ginnala; Acer platanoides; Acer tataricum ssp. ginnala; ploidy manipulation; sterility

\section{Introduction}

Maples (Acer sp.) are popular landscape trees often identified by commonly having palmately lobed leaves and characteristic schizocarps (joined samaras). However, many species differ from the archetype palmately lobed leaves and most species are not particularly desired for their flowers or fruit, though few exceptions exist (e.g., 'Flame' amur maple grown for its red schizocarps). In 2014, overall U.S. sales of maples exceeded $\$ 173$ million, which accounted for $31 \%$ of the nearly $\$ 562$ million of deciduous shade trees sold nationally [1]. Much of the nursery stock produced around the country is marketed to population centers in the upper Midwest and New England regions. In fact, Oregon, the leading shade tree production state in the U.S., ships approximately $80 \%$ of its nursery plant material out of state and historically has relied on regions in the eastern part of the U.S. as principle markets.

With the nearly complete loss of elms and ash from the market due to Dutch elm disease [2] and emerald ash borer [3], respectively, the nursery and landscape industries are more reliant on maples to fill the urban canopy. However, many maples have the significant drawback of being weedy. Several species have escaped cultivation and become invasive to the point of being banned in some states, which has resulted in a significant decline of staple species in historically key markets such as New England. 
Among the most widely used maples, Norway maple (A. platanoides) became popular in the U.S. in the mid- to late-1800s and continues to be widely used as a street and shade tree. Following previous devastating losses of elm trees from Dutch elm disease, large numbers of Norway maples were planted. Desirable forms include columnar growth habit, red leaves, and cultivars with improved fall color. Norway maples grow well under a wide range of conditions including sand to clay and acid to calcareous soils. It is hardy from USDA Zone 4 to 7 and tolerates hot, dry conditions better than sugar maple. Furthermore, Norway maple is tolerant of air pollution, including ozone and sulfur dioxide, making it ideal for use as a street tree. However, a major problem with Norway maple is that it has become naturalized to the point of invasiveness in forests of New England. Between 2009 and 2014, sales of Norway maple fell by more than $5 \%$ from $\$ 14.4$ million to $\$ 13.6$ million but many growers have seen much more dramatic declines in sales. Based on conversations with leading shade tree growers, this downward trend continues. Robinson Nursery, an Oregon shade tree grower, estimates their market is down $90 \%$ from a decade ago. Their data indicates they sold approximately 25,000 Norway maples annually between 2000 and 2006, but today they sell closer to 3000. It is likely that a continued downward trend will be observed unless alternative cultivars are introduced.

Other street trees that previously were dominant in the market have seen precipitous declines in sales due to emerging pests. Ash (Fraxinus spp.) was a leading street tree until recently; however, with the emergence of emerald ash borer as a major pest, the viability of ash as a commercial crop has been reduced. Sales declined from nearly \$15 million in 2009 to less than \$10 million in 2014 [1] and the pest continues to devastate the Midwestern urban tree canopy, thus one would expect ash sales to continue to fall. Since currently there is not a viable source of resistance in the U.S., it is imperative we have alternatives in the nursery and landscape industry to replace street trees in American cities.

Ecological and economic harm occurs when ornamental plants escape cultivation and displace native flora, which requires costly action on the part of land managers [4]. Furthermore, legislation preventing nurseries from producing and selling these species causes economic harm to growers. The fruit (winged samaras or schizocarps) that are so well recognized in the landscape are also notorious for introducing unwanted maple seedlings into both the urban and natural landscapes. Currently, there are three maples species [Acer tataricum ssp. ginnala (Amur maple), A. platanoides, A. pseudoplatanus (sycamore maple)] listed as noxious weeds in Connecticut and Massachusetts. Of these three species, two are banned from the state of Massachusetts and one is banned in Connecticut [5]. While not yet listed in other regions of the country, these species are widely distributed and have naturalized over large areas (Figure 1). Norway maple is extremely shade tolerant and its phenology is such that it releases its seeds at an appropriate time for survival (early fall) and natural cold stratification. This is in contrast to red maple (A. rubrum), for example, that has mature schizocarps during summer when summer drought often prevents recalcitrant seeds from surviving.

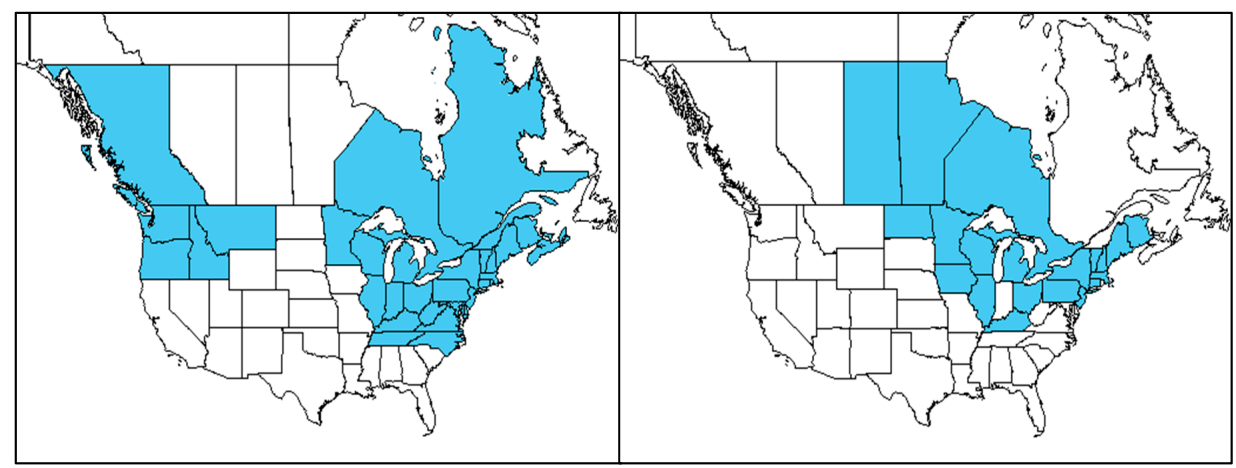

(a)

(b)

Figure 1. Distribution (filled regions) of naturalized (a) Norway maple and Amur maple (b) from the USDA PLANTS database https://plants.sc.egov.usda.gov/java/. 
Species listed as "maple, other" accounted for more than \$32 million in sales during 2014 [1]. This is important to note because many of these other species produce copious amounts of viable seed that have the potential to escape cultivation and create similar ecological issues as Norway and Amur maple. It is worth noting that Norway maple was introduced into the U.S. around 1756 [6] and there was a lag phase before populations reached levels sufficient to cause ecological harm. It is reasonable to predict that with time; other species of maples have the potential to spread from cultivation. They, too, could become noxious weeds and eventually be banned from production or sale. As such, the methods and results described herein have application in other maple species.

Fertility of weedy species can be reduced using a number of techniques including ploidy manipulation. Other more technical methods such as gene editing and transgenics are far more expensive, require intimate knowledge of genomes of interest, and regeneration systems to recover whole plants from in vitro transgenic cell lines [7], all of which are generally lacking for maples. Furthermore, negative public perception and the cost of navigating regulatory approval is estimated to be in the tens of millions of dollars [8]. Ploidy manipulation to develop sterile triploids is relatively inexpensive and proven effective in many plant taxa. Inducing polyploids using chemical means, particularly the dinitroaniline herbicide, oryzalin, has become commonplace in woody plants including Acer [9-11]. Ploidy is the number of chromosome sets found in an organism and most organisms have two sets (diploids $=2 x$ ) but plants are capable of existing with more than two sets of chromosomes. Plants can be rendered sterile, or at least have their fertility reduced, by producing cultivars with an odd number of chromosome sets-most commonly three sets (i.e., triploids $=3 x$ ) [12]. Sterility resulting from triploidy occurs because plants with an odd ploidy number cannot be equally divided during meiosis such that daughter cells contain between $n$ and $2 n$ chromosomes [13]. In most cases where rare seedlings do arise from triploids, they often are aneuploids with reduced fitness and pose little or no ecological threat to escape cultivation [14]. This is a longstanding and common technique that resulted in seedless food crops such as bananas [15], watermelons [16], and some cultivars of grapes [17]. In nature, triploids can occur through production of unreduced (2n) gametes [14]. However, plant breeders can double the chromosomes of a diploid plant using various chemicals and the resulting tetraploid $(4 x)$ plant is then crossed with the diploid plant to create triploids. Induced polyploidy has been used in a wide variety of woody plants [7]. However, fewer examples are found for woody ornamentals. Lehrer et al. (2008) developed tetraploids of Japanese barberry (Berberis thunbergii), a weedy species in New England [18]. Their use of ploidy manipulation resulted in plants later released as 'UCONNBTCP4N' USPP 30,095 Crimson Cutie ${ }^{\circledR}$ and 'UCONNBTB048' USPP 30,127 Lemon Glow ${ }^{\circledR}$ barberry. These examples are interesting, as they were found to be nearly sterile at the autotetraploid level, presumably due to multivalent formation, which avoided the need to proceed to the next generation. Rounsaville et al. (2011) compared fertility of diploid to triploid cytotypes of maidengrass (Miscanthus sinensis) and found the latter to have as low as $0.7 \%$ fertility relative to the wild type [19]. Phillips et al. (2016) developed triploid flowering pears (Pyrus sp.) that ranged from $0 \%$ to $34 \%$ relative fertility compared to diploid controls-a study that highlights the need for extensive and thorough testing of resulting triploids [20]. Campsis $\times$ tagliabuana 'Chastity' is a triploid cultivar of trumpet creeper that was developed by crossing a diploid cultivar with an oryzalin-induced tetraploid that is reported to have $>99 \%$ reduction in fertility compared to diploid C. radicans [21].

Maples generally are diploids with two copies of 13 base chromosomes $(2 n=2 x=26)$. To address the issue of weediness among maples, we developed triploids $(3 x=39)$ that we hoped would exhibit reduced fertility and thus lessen the potential negative impacts of weedy and potentially invasive maple species. Introducing cultivars of maple with reduced fertility would allow land managers to maintain ecologically well-adapted species that thrive in difficult urban environments. Cultivars with reduced fertility would support the urban forests where they are planted and also protect the surrounding natural environments by preventing escape from cultivation. Furthermore, such cultivars support the sustainability of nursery producers who have relied heavily on these economically important species but have suffered due to the decline in demand as a result of their weediness. To address the 
need for sterile maple cultivars, the objectives of the current research were to (1) develop tetraploids (2) backcross to diploids to produce triploids and (3) evaluate fertility as plants began flowering to determine if triploid maples exhibit reduced fertility. While we discuss the methods used to generate tetraploids, we do not consider these necessarily to be optimized methods.

\section{Materials and Methods}

\subsection{Inducing Polyploidy Using Expanding Norway Maple Buds}

Dormant plants of 'Crimson King', 'Emerald Queen', and 'Royal Red' were received bareroot from J. Frank Schmidt \& Sons Co (Boring, OR, USA) during January 2010. Roots were trimmed to encourage new growth and all trees were toped to $1.8 \mathrm{~m}$ before potting into $60 \mathrm{~L}$ containers filled with $70 \%$ unaged douglas-fir bark, $15 \%$ peat, and $15 \%$ pumice and topdressed with label rate of control-release fertilizer (19-2.63-9.96, Apex ${ }^{\circledR}$, J.R. Simplot, Boise, ID, USA). Trees were maintained in a glasshouse with day/night set temperatures of $22 / 18^{\circ} \mathrm{C}$ and $16 \mathrm{~h}$ supplemental lighting provided by high-intensity discharge lamps.

In 2010, shoot tips were exposed by removing leaves as buds were emerging from dormancy and treatments were applied to two plants per cultivar. A 5-day treatment was applied to between 12 and 23 meristems per tree from March 11 to March 15 and a 3-day treatment was applied to between 3 and 13 previously untreated meristems from April 2 and 5 (Table 1). All treatments were $150 \mu \mathrm{M}$ oryzalin supplied as Surflan AS (United Phosphorous, King of Prussia, PA, USA) solidified with $0.8 \%$ agar. Following this, $1.5 \mathrm{~mL}$ of the melted agar-oryzalin solution was distributed into microcentrifuge tubes that were carefully placed over meristems. Ploidy analysis was conducted on surviving branches during July.

Table 1. Meristems of Acer platanoides (Norway maple) cultivars after treating with $150 \mu \mathrm{M}$ oryzalin supplied as Surflan and solidified with $0.8 \%$ agar during 2010 . Meristems were exposed by removing bud scales and submerging in agar-solidified oryzalin solution for 3 or $5 \mathrm{~d}$.

\begin{tabular}{|c|c|c|c|c|c|c|c|c|}
\hline Cultivar & $\operatorname{Rep}^{1}$ & Trt (d) ${ }^{2}$ & No. Meristems ${ }^{3}$ & Bud $^{4}$ & Dead (\%) & $2 x(\%)$ & $2 x+4 x(\%)$ & $4 x(\%)^{5}$ \\
\hline Emerald Queen & 1 & 5 & 23 & 0 & $21(91)$ & $2(9)$ & 0 & 0 \\
\hline Emerald Queen & 2 & 5 & 14 & 0 & $9(64)$ & $5(36)$ & 0 & 0 \\
\hline Royal Red & 1 & 5 & 15 & 0 & $11(73)$ & $2(13)$ & $1(7)$ & $1(7)$ \\
\hline Crimson King & 1 & 5 & 17 & $1(6)$ & $14(82)$ & $2(12)$ & 0 & 0 \\
\hline Crimson King & 2 & 5 & 16 & 0 & $13(81)$ & $3(19)$ & 0 & 0 \\
\hline Emerald Queen & 1 & 3 & 16 & $1(6)$ & $10(63)$ & $5(31)$ & 0 & 0 \\
\hline Royal Red & 2 & 3 & 3 & 0 & 0 & $2(67)$ & $1(33)$ & 0 \\
\hline Crimson King & 1 & 3 & 4 & 0 & $3(75)$ & 0 & $1(25)$ & 0 \\
\hline Crimson King & 2 & 3 & 2 & 0 & $1(50)$ & $1(50)$ & 0 & 0 \\
\hline
\end{tabular}

${ }^{1}$ Rep $=$ replicate, ${ }^{2} \operatorname{Trt}(\mathrm{d})=$ treatment $($ days $),{ }^{3}$ No. meristems $=$ number of meristems, ${ }^{4}$ Meristem did not expand/elongate following treatment but did not appear dead., ${ }^{5}$ All meristems later reverted to $2 x$.

In 2011, trees were moved into a glasshouse on Jan 7 under conditions described above. On Feb 21, bud scales were removed from swollen, unbroken buds to expose meristems. Meristems treated for 5 or $6 \mathrm{~d}$, each with $100 \mu \mathrm{M}$ oryzalin supplied as Surflan solidified with $0.8 \%$ using plastic caps filled with $2 \mathrm{~mL}$ of solution (Figure 2). Ploidy analysis was conducted on surviving branches during July. 


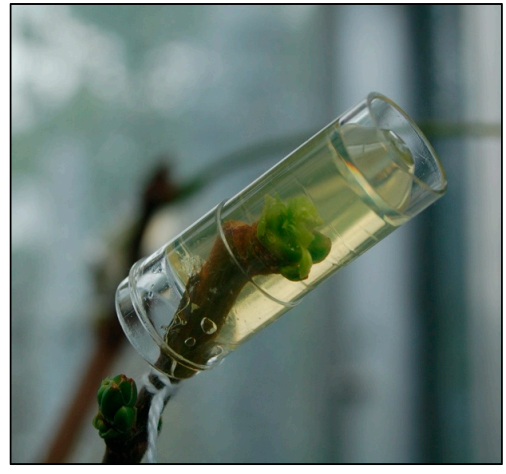

(a)

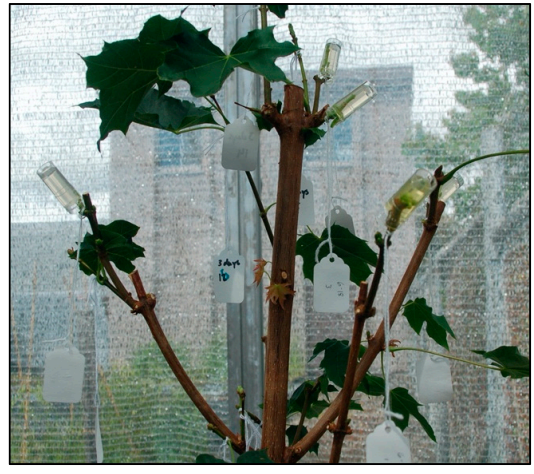

(b)

Figure 2. The 2011 application of $100 \mu \mathrm{M}$ oryzalin to meristems of Acer platanoides 'Emerald Queen'. (a) a representative tree that was cut back and treated as meristems emerged from dormancy and

(b) closeup of meristem exposed by removing bud scales as emerged after dormancy.

\subsection{Inducing Polyploidy of Using Germinated Seedlings}

Norway maple seed was collected during July 2010 from three sources in Corvallis, OR including 223 seed of a green cultivar on Bridgeway St., 1200 seed of a green cultivar on Jefferson St. on Oregon State University campus, and 316 seed of 'Crimson King' at the Lewis-Brown Horticulture Research Farm. Cultivar identity was not confirmed using molecular or other tools but phenotype of both Jefferson St. and Bridgeway St. collections were similar to 'Emerald Queen'. Seeds were stratified for $90 \mathrm{~d}$ at $3{ }^{\circ} \mathrm{C}$ and then sown in $10 \times 20 \mathrm{~cm}$ flats filled with a 1 bagged potting mix Sunshine LA4 P (Sun Gro Horticulture, Agawam, MA, USA): 1 douglas-fir-based media. Flats were maintained under glasshouse conditions described above with the modification of no supplemental lighting.

After the first pair of true leaves emerged, the meristem was treated for five consecutive days with $25 \mu \mathrm{L}$ of $150 \mu \mathrm{M}$ oryzalin solution supplied as Surflan solidified with $0.55 \%$ agar (Figure 3 ). There were 155 seedlings of Bridgeway St. selection, 231 seedlings of Jefferson St. selection, and 154 seedlings of 'Crimson King' treated. Surviving seedlings were transplanted into $237 \mathrm{~cm}^{3}$ pots and allowed to grow under glasshouse conditions. All seedlings were fertilized every 7 to $10 \mathrm{~d}$ with liquid fertilizer with micronutrients (20-8.74-16.6, Jack's Professional, J.R. Peters Inc., Allentown, PA). During August 2011, fully expanded and mature leaves of each surviving seedling were run on the flow cytometer to determine change in ploidy.

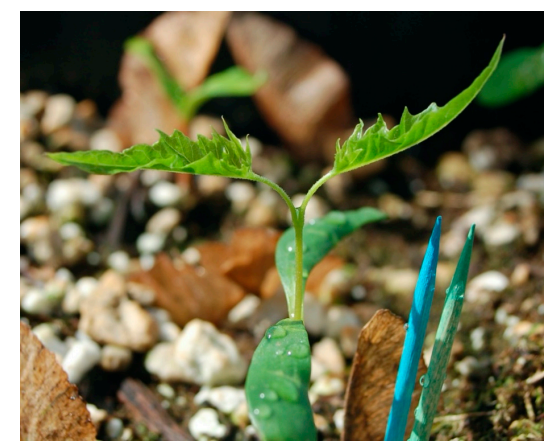

Figure 3. A droplet of $150 \mu \mathrm{M}$ oryzalin semi-solidified using $0.2 \%$ agar was applied to the meristem of a Norway maple seedling.

Amur and trident maple seed were collected from a single source each from an unidentified selection on Oregon State University, Corvallis, OR campus during 2011. Seed were stratified for treatment in 2012. Treatment and handling were all conducted as described for Norway maple. 


\subsection{Assessing Ploidy Level}

Flow cytometry analysis of extracted nuclei stained with DAPI (4',6-diamidino-2-phenylindole) was carried out according to Contreras and Shearer [10] with the modification that only one sample was used for parent and seedlings.

\subsection{Interploidy Crossing}

During 2014 and 2015, a subset of Amur maple trees flowered and were used in controlled crosses between tetraploids, diploids, and mixoploids for which the LII was confirmed as tetraploid by measuring pollen. During 2014, we conducted reciprocal interploidy crosses that yielded 56 seed from 165 pollinated flowers, resulting in few triploids (data not shown). During 2015, we made 828 reciprocal crosses and collected 78 seeds (data not shown). Based on observations of relatively low yield from a substantial investment of time, we opted to field plant diploids and tetraploids of Amur and trident maples during 2015 to facilitate interploidy crossing (Figure 4). Additionally, we planted several diploids of Acer tataricum that were collected from as seed from a single source on the Oregon State University campus, Corvallis, OR. These new plantings added to Norway maples that were field planted during March 2014. Additionally, 54 trees (V01.01 through V01.54) were planted at the Smith Horticultural Research Farm in a single row including six diploids, 12 cytochimeras, and 36 tetraploids. Of the 54 trees, 34 were derived from the Jefferson St. seed source, 16 were derived from 'Crimson King', and four were derived from the Bridgeway St. seed source.

\begin{tabular}{|c|c|c|c|c|}
\hline & & & $74.232 x \mathrm{AT}$ & \\
\hline $71.224 x \mathrm{AP}$ & $72.224 x \mathrm{AB}$ & & $74.224 x \mathrm{AG}$ & \\
\hline $71.214 x \mathrm{AP}$ & $72.212 x \mathrm{AB}$ & & $74.212 x \mathrm{AG}$ & \\
\hline $71.204 x \mathrm{AP}$ & $72.202 x / 4 x \mathrm{AB}$ & & $74.202 x$ AT & \\
\hline $71.194 x \mathrm{AP}$ & $72.194 x \mathrm{AB}$ & $73.194 x \mathrm{AB}$ & $74.194 x \mathrm{AG}$ & \\
\hline $71.184 x \mathrm{AP}$ & $72.182 x / 4 x \mathrm{AB}$ & $73.182 x / 4 x \mathrm{AB}$ & \multirow{18}{*}{ 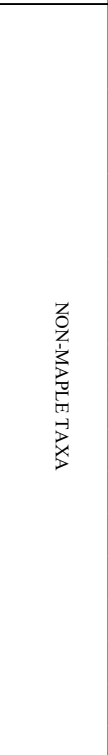 } & $75.184 x \mathrm{AG}$ \\
\hline $71.174 x$ AP & $72.173 x \mathrm{AB}$ & $73.174 x \mathrm{AB}$ & & $75.172 x$ AT \\
\hline $71.164 x \mathrm{AP}$ & $72.162 x \mathrm{AB}$ & OPEN & & $75.162 x \mathrm{AG}$ \\
\hline $71.154 x \mathrm{AP}$ & $72.154 x \mathrm{AB}$ & \multirow{15}{*}{ 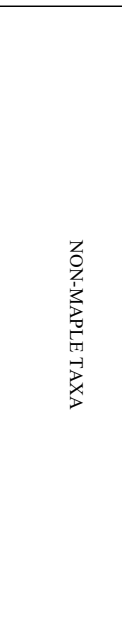 } & & $75.154 x \mathrm{AG}$ \\
\hline $71.144 x \mathrm{AP}$ & $72.142 x / 4 x \mathrm{AB}$ & & & $75.142 x \mathrm{AT}$ \\
\hline $71.134 x \mathrm{AP}$ & $72.132 x / 4 x \mathrm{AB}$ & & & $75.132 x / 4 x \mathrm{AG}$ \\
\hline $71.124 x \mathrm{AP}$ & \multirow{12}{*}{ 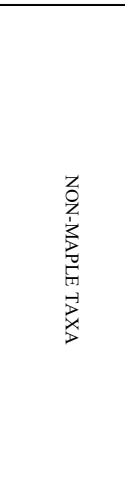 } & & & $75.124 x \mathrm{AG}$ \\
\hline $71.114 x \mathrm{AP}$ & & & & $75.114 x \mathrm{AG}$ \\
\hline $71.104 x \mathrm{AP}$ & & & & $75.102 x \mathrm{AG}$ \\
\hline $71.094 x \mathrm{AP}$ & & & & $75.094 x \mathrm{AG}$ \\
\hline $71.084 x \mathrm{AP}$ & & & & $75.082 x$ AT \\
\hline $71.074 x \mathrm{AP}$ & & & & $75.074 x \mathrm{AP}$ \\
\hline $71.064 x \mathrm{AP}$ & & & & 75.06 AP Royal Red \\
\hline $71.054 x \mathrm{AP}$ & & & & $75.054 x \mathrm{AP}$ \\
\hline $71.044 x$ AP & & & & 75.04 AP Deborah \\
\hline $71.034 x \mathrm{AP}$ & & & & $75.034 x \mathrm{AP}$ \\
\hline $71.024 x \mathrm{AP}$ & & & & $75.024 x$ AP \\
\hline $71.014 x \mathrm{AP}$ & & & & $75.014 x \mathrm{AP}$ \\
\hline Row 71 & Row 72 & Row 73 & Row 74 & Row 75 \\
\hline
\end{tabular}

Figure 4. Field map for Acer buergerianum (AB), Acer tataricum ssp. ginnala (AG), A. platanoides (AP), and A. tataricum (AT) at the Lewis Brown Horticulture Research Farm, Corvallis, OR including diploids $(2 x)$, triploids $(3 x)$, mixoploids $(2 x / 4 x)$ and tetraploids $(4 x)$. For Row 71 , all tetraploids were derived from Jefferson St. seed source except 71.02, 71.10, 71.12, and 71.22, which were derived from 'Crimson King'. Trees 75.01, 75.03, and 75.07 were derived from the Jefferson St. seed source and trees 75.02 and 75.05 were derived from 'Crimson King'. For Row 76, all tetraploids were derived from Jefferson St. seed source except 76.05, which was derived from 'Crimson King'. 


\section{Results}

\subsection{Inducing Polyploidy Using Expanding Norway Maple Buds}

Survival was low in all treatments of buds during 2010 and 2011 (Tables 1 and 2). Ploidy analysis of the 2010 treatments identified five tetraploid meristems of 'Royal Red' - four from the $5 \mathrm{~d}$ treatment and one from the $3 \mathrm{~d}$ treatment. During August 2010, 51 buds were sent for propagation and field testing with a commercial nursery. During March and April 2011, we assessed ploidy from these plants and found all were diploid, indicating complete reversion of these meristems even in those that previously appeared to be homogeneous (non-chimeric) tetraploids. Thus, no tetraploids were obtained from this treatment. No polyploids were identified from the 2011 treatments (Table 2).

Table 2. Meristems of Acer platanoides cultivars after treating with $100 \mu \mathrm{M}$ oryzalin supplied as Surflan and solidified with $0.8 \%$ agar during 2011. Meristems were exposed by removing bud scales and submerging in agar-solidified oryzalin solution for 5 or $6 \mathrm{~d}$.

\begin{tabular}{cccccc}
\hline Cultivar & Rep & Trt (d) & No. Meristems & Dead (\%) & $\mathbf{2 x}$ \\
\hline Crimson King & 1 & 5 & 23 & $20(87)$ & $3(13)$ \\
Crimson King & 2 & 5 & 11 & $7(64)$ & $4(36)$ \\
Emerald Queen & 1 & 5 & 11 & $9(82)$ & $2(18)$ \\
Emerald Queen & 2 & 5 & 12 & $10(83)$ & $2(17)$ \\
Royal Red & 1 & 5 & 14 & $9(64)$ & $5(36)$ \\
Royal Red & 2 & 5 & 13 & $11(85)$ & $2(15)$ \\
Crimson King & 1 & 6 & 2 & $2(100)$ & 0 \\
Crimson King & 2 & 6 & 4 & $3(75)$ & $1(25)$ \\
Emerald Queen & 1 & 6 & 6 & $6(100)$ & 0 \\
Emerald Queen & 2 & 6 & 3 & $3(100)$ & 0 \\
Royal Red & 1 & 6 & 1 & 0 & $1(100)$ \\
Royal Red & 2 & 6 & 1 & $1(100)$ & 0 \\
\hline
\end{tabular}

\subsection{Inducing Polyploidy of Using Germinated Seedlings}

\subsubsection{Norway Maple}

Stable tetraploids of Norway maple were obtained in 2011 by treating meristems of germinated seedlings at the cotyledon or first true leaf stage (Table 3). Percent tetraploids ranged from 5\% to 35\% of treated seedlings. Mortality ranged from 23\% to 60\% of treated seedlings. During 2012, 11 tetraploid genotypes were propagated by a commercial nursery. Nine of these genotypes were confirmed to be stable, homogeneous (non-chimeric) tetraploids during spring 2013, after leaves emerged. These nine were transplanted to the Lewis Brown Horticulture (LBH) farm in Corvallis, OR during fall 2013.

Table 3. Seedlings of Acer platanoides (Norway maple) collected and treated during 2010, for 5 d with 25 $\mu \mathrm{L}$ of $150 \mu \mathrm{M}$ oryzalin supplied as Surflan $+0.55 \%$ agar for $5 \mathrm{~d}$. Ploidy analysis conducted during 2011 .

\begin{tabular}{|c|c|c|c|c|c|}
\hline Cultivar/Collection & Seedlings Treated & Dead (\%) & $2 x(\%)^{1}$ & $2 x+4 x(\%)^{1}$ & $4 x(\%)^{1}$ \\
\hline Bridgeway St. ${ }^{2}$ & 155 & $61(39)$ & $75(48)$ & $12(8)$ & $7(5)$ \\
\hline Crimson King & 154 & $92(60)$ & $30(19)$ & $8(5)$ & $24(16)$ \\
\hline Jefferson St. ${ }^{2}$ & 231 & $52(23)$ & $67(29)$ & $30(13)$ & $82(35)$ \\
\hline
\end{tabular}

${ }^{1}$ Percent of treated seedlings at each ploidy level. ${ }^{2}$ Seed collected in Corvallis, OR from trees on Bridgeway St. and Jefferson St., respectively. Both trees were green foliage types that resembled 'Emerald Queen' but were not confirmed by molecular or other means. 


\subsubsection{Amur Maple}

There was a low percentage of both mixoploids and tetraploids that resulted from meristem treatment of Amur maple (Table 4). Six homogenous tetraploids were recovered along with six mixoploids, of which three reverted to diploids, two stabilized as tetraploids, and one remained a cytochimera. There was no mortality following seedling treatment, in contrast to the relatively high percentage of dead seedlings among cultivars of Norway maple. Leaves of Amur maple tetraploids were darker green and thicker than diploids (Figure 5).

Table 4. Ploidy of seedlings of Acer buergerianum (trident maple) and A. tataricum ssp. ginnala (Amur maple) treated during 2012, for $5 \mathrm{~d}$ with $25 \mu \mathrm{L}$ of $150 \mu \mathrm{M}$ oryzalin supplied as Surflan $+0.55 \%$ agar applied to meristems at the first true leaf stage.

\begin{tabular}{cccccc}
\hline Species & Treated (No.) & $\mathbf{2 x} \mathbf{( \% )}$ & $\mathbf{3 x} \mathbf{( \% )}$ & $\mathbf{2 x + 4 x ( \% )}$ & $\mathbf{4 x}(\mathbf{\%})$ \\
\hline A. buergerianum & 244 & $220(91)$ & $1(0.004)$ & $15(6)$ & $8(3)$ \\
A. tataricum spp. ginnala & 198 & $186(94)$ & 0 & $6^{1}(3)$ & $6(3)$ \\
\hline
\end{tabular}

${ }^{1}$ Three later reverted to diploids and two stabilized at tetraploids.

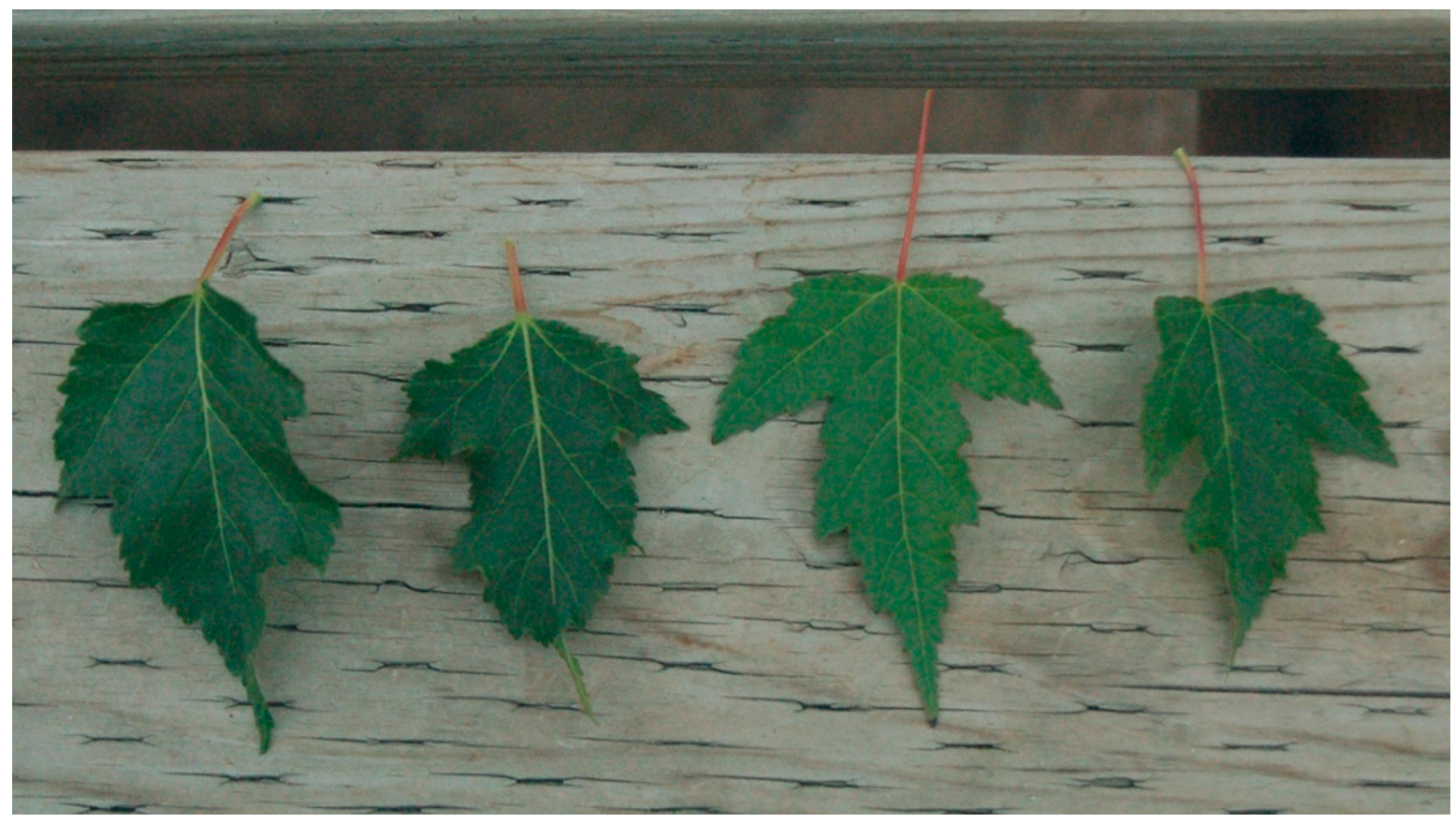

(a)

(b)

Figure 5. Two leaves of tetraploid (a) and two leaves of diploid (b) forms of Acer tataricum ssp. ginnala.

\subsubsection{Trident Maple}

There was a low percentage of tetraploids (3\%) and mixoploids (6\%) recovered following treatment of trident maple (Table 4). Of particular interest, a single triploid was found following treatment but it is unclear if this was due to treatment or unreduced gamete(s). There was no mortality following seedling treatment. 


\subsection{Interploidy Crossing}

\subsubsection{Norway Maple}

In 2014, one Norway maple tetraploid plant flowered, indicating that precocious flowering is possible, albeit at a low percentage. This tree did not set fruit and has not flowered since. In 2015, several more trees flowered but none set fruit. In 2016, one tetraploid set fruit, all of which were collected, cold-stratified, and sown (Table 5). Fifty-four of 416 seeds germinated (13\%) and yielded 47 triploids (89\%), 5 tetraploids (9\%), and 1 pentaploid (2\%). During 2017, no tetraploids of Norway maple flowered-only Amur maple tetraploids flowered and produced seed (Table 6). During the 2018 flowering season, four plants previously identified as tetraploids flowered, two of which produced 43 and 19 seeds, respectively (Table 7). No flowering was observed from diploid or mixoploid plants. All 43 seeds from V01.34 were direct seeded in field raised beds but none germinated. Across all taxa and ploidy levels we had no germination in field beds. V01.45 produced 19 seeds, 17 of which germinated in containers. However, ploidy was retested and it was confirmed that V01.34 and V01.45 had reverted to diploid, therefore neither tetraploid that flowered set seed during 2018. In 2019, flowering was observed in 5 diploids (44\%), no mixoploids, and 4 tetraploids (16\%). During the 2019 flowering season, V01.34 flowered again and produced 404 seeds, nine of which germinated (Table 7). Ploidy analysis has not been conducted on seedlings from 2018 and 2019 flowering seasons due to time constraints and efforts to create efficiencies in the breeding process. We have opted to delay ploidy analysis on these and future populations based on the high percentage of triploids from 2016 flowering season $(89 \%)$, which indicated it is likely that most seedlings will be triploid when collected from tetraploids. In 2020, flowering was observed in 3 diploids (33\%), 2 mixoploids (18\%) and 2 tetraploids $(6 \%)$ with seed collection ongoing. None of the triploids have flowered at this time.

Table 5. Ploidy analysis using flow cytometry of seedlings resulting from open-pollination of field grown Acer platanoides (Norway maple) tetraploids. Seed were collected from 2016 flowering season and evaluated in 2017.

\begin{tabular}{ccccccc}
\hline Field Location & Seed (No.) & Seedlings (No.) & $\mathbf{2 x}(\mathbf{\%})$ & $\mathbf{3 x}(\mathbf{\%})$ & $\mathbf{4 x}(\mathbf{\%})$ & $\mathbf{5 x}(\mathbf{\%})$ \\
\hline 71.03 & 416 & 54 & 0 & $48(89)$ & $5(9)$ & $1(2)$ \\
\hline
\end{tabular}

Table 6. Ploidy analysis using flow cytometry of seedlings resulting from open-pollination of field grown Acer tatricum ssp. ginnala (Amur maple) tetraploids. Seed were collected from 2016 and 2017 flowering seasons, respectively, and evaluated the following spring.

\begin{tabular}{|c|c|c|c|c|c|c|}
\hline \multirow[t]{2}{*}{ Field Location } & \multirow[t]{2}{*}{ Seed (No.) } & \multirow[t]{2}{*}{ Seedlings (No.) $^{1}$} & \multicolumn{4}{|c|}{ No. Plants at Each Ploidy Level (\% of Tested) } \\
\hline & & & $2 x$ & $3 x$ & $4 x$ & $5 x$ \\
\hline \multicolumn{7}{|c|}{2016} \\
\hline 74.19 & 1277 & 176 & $1(1)$ & $106(81)$ & $17(13)$ & $7(5)$ \\
\hline 74.22 & 562 & 29 & $1(3)$ & $25(86)$ & $3(10)$ & 0 \\
\hline 75.11 & 869 & 94 & 0 & $18(95)$ & $1(5)$ & 0 \\
\hline 75.15 & 247 & 9 & 0 & $3(33)$ & $6(67)$ & 0 \\
\hline 75.18 & 619 & 64 & 0 & $59(94)$ & $3(5)$ & $1(2)$ \\
\hline \multicolumn{7}{|c|}{2017} \\
\hline 74.19 & 1884 & 530 & $6(1)$ & 445 (97) & $8(2)$ & 0 \\
\hline 75.11 & 7 & 0 & - & - & - & 0 \\
\hline 75.15 & 297 & 28 & 0 & $22(79)$ & $6(21)$ & 0 \\
\hline
\end{tabular}

${ }^{1}$ Seedling number does not correspond to plants analyzed for ploidy level in all cases, as plants died or did not produce sufficient leaf material for analysis, presumably due to verticillium wilt. 
Table 7. Number of seeds and seedlings resulting from open-pollination of field grown Acer buergerianum, A. tataricum ssp. ginnala, and $A$. platanoides including seeds collected from diploid, cytochimera $(2 x+$ $4 x$ ) and tetraploid branches. Seed were collected from 2018 and 2019 flowering season.

\begin{tabular}{|c|c|c|c|c|c|}
\hline Species & Location & Ploidy $^{1}$ & Seed (No.) & Sowing Method $^{2}$ & Germinated (\%) \\
\hline \multicolumn{6}{|c|}{2018} \\
\hline A. buergerianum & 72.16 & $2 x$ & 76 & Field & 0 \\
\hline A. buergerianum & 72.16 & $2 x$ & 38 & Containers & $3(8)$ \\
\hline A. buergerianum & 72.18 & $2 x$ & 312 & Field & 0 \\
\hline A. buergerianum & 72.18 & $2 x$ & 156 & Containers & $11(7)$ \\
\hline A. buergerianum & 72.21 & $2 x$ & 374 & Field & 0 \\
\hline A. buergerianum & 72.21 & $2 x$ & 187 & Containers & $9(5)$ \\
\hline A. buergerianum & 72.18 & $2 x+4 x$ & 19 & Field & 0 \\
\hline A. buergerianum & 72.18 & $2 x+4 x$ & 19 & Containers & $3(16)$ \\
\hline A. buergerianum & 72.18 & $4 x$ & 29 & Field & 0 \\
\hline A. buergerianum & 72.18 & $4 x$ & 29 & Containers & $3(10)$ \\
\hline A.t. ssp. ginnala & 74.22 & $4 x$ & 1694 & Field & 0 \\
\hline A.t. ssp. ginnala & 74.22 & $4 x$ & 847 & Containers & $150(18)$ \\
\hline A.t. ssp. ginnala & 75.11 & $4 x$ & 174 & Field & 0 \\
\hline A.t. ssp. ginnala & 75.11 & $4 x$ & 87 & Containers & 0 \\
\hline A.t. ssp. ginnala & 75.12 & $4 x$ & 30 & Field & 0 \\
\hline A.t. ssp. ginnala & 75.12 & $4 x$ & 29 & Containers & 0 \\
\hline A.t. ssp. ginnala & 75.15 & $4 x$ & 162 & Containers & $10(6)$ \\
\hline A. platanoides & 71.16 & $4 x$ & 68 & Field & 0 \\
\hline A. platanoides & V01.34 3 & $4 x$ & 43 & Field & 0 \\
\hline A. platanoides & V01.45 3 & $4 x$ & 19 & Containers & $17(89)$ \\
\hline \multicolumn{6}{|c|}{2019} \\
\hline A. buergerianum & 72.13 & $2 x$ & 142 & Containers & $2(1)$ \\
\hline A. buergerianum & 72.18 & $2 x$ & 377 & Containers & $1(0.3)$ \\
\hline A. buergerianum & 72.20 & $2 x$ & 113 & Containers & $4(4)$ \\
\hline A. buergerianum & 73.18 & $2 x$ & 66 & Containers & $9(3)$ \\
\hline A. buergerianum & 72.13 & $2 x+4 x$ & 133 & Containers & 0 \\
\hline A. buergerianum & 72.18 & $2 x+4 x$ & 1136 & Containers & $11(1)$ \\
\hline A. buergerianum & 72.20 & $2 x+4 x$ & 423 & Containers & $9(2)$ \\
\hline A. buergerianum & 73.19 & $2 x+4 x$ & 160 & Containers & $2(1)$ \\
\hline A.t. ssp. ginnala & 75.15 & $4 x$ & 775 & Containers & $72(9)$ \\
\hline A.t. ssp. ginnala & 107.07 & $4 x$ & 152 & Containers & 0 \\
\hline A.t. ssp. ginnala & 109.05 & $3 x$ & 5 & Containers & 0 \\
\hline A.t. ssp. ginnala & 112.06 & $3 x$ & 79 & Containers & 0 \\
\hline A.t. ssp. ginnala & 114.02 & $3 x$ & 16 & Containers & 0 \\
\hline A.t. ssp. ginnala & 107.12 & $5 x$ & 27 & Containers & 0 \\
\hline A. platanoides & V01.34 3 & $2 x$ & 404 & Containers & $9(2)$ \\
\hline
\end{tabular}

${ }^{1}$ When seeds were collected from respective branches they were tested for ploidy level and some trees were found to be cytochimeras including some trees with $2 x, 2 x+4 x$, and $4 x$ branches. Different ploidy levels were kept separate for analysis. ${ }^{2}$ During 2018 seed sowing, direct field seeding was attempted to increase efficiency of production but resulted in no germination. ${ }^{3}$ Trees were tested during 2018 and determined to have reverted to $2 x$. For 2019 flowering V01.34 was labeled as $2 x$, however additional sampling is required to confirm if the entire tree has reverted or specific branches.

\subsubsection{Amur Maple}

During 2016, seven tetraploid Amur maples flowered and five set seed. These resulted in two diploids, 211 triploids, 30 tetraploids, and eight pentaploids (Table 5). Plant 74.19 was the most prolific in terms of production with 1277 seeds, 176 seedlings, and 106 triploids. However, the highest percentage of triploids were recovered from plant 75.11 , which yielded $95 \%$ triploids. Overall, the percentage of triploids recovered from 2016 flowering ranged from $33 \%$ to $95 \%$. It is unclear why plant 75.15 had such a low percentage of triploids recovered since it had diploids on either side within its row, thus diploid pollen was presumably not limiting.

During 2017, three tetraploids flowered and resulted in a high percentage of triploids (Table 6). Percentage triploids included 79\% from plant 75.15, up from 33\% in 2016. Plant 74.19 yielded $97 \%$ triploids and again was the most prolific producer of seed and seedlings.

During 2018, eight tetraploids flowered and produced 3347 seeds and 160 seedlings (Table 7). As with the Norway maples, seed lots were split between field beds and containers and none of 
the 2222 seeds that were field planted germinated. Of the 1125 seeds sown in containers, $160(14 \%)$ germinated. The mean percent of triploids from previous years' flowering was $81 \%$, thus we expect similar results from 2018, 2019, and future flowering seasons. By the end of the 2018 season, all Amur maples from the original tetraploid population except 75.15 experienced severe verticillium wilt (Verticillium dahliae) infestation, were killed to the ground and removed from the field.

During 2019, the remaining tetraploid (accession 75.15) from the original population flowered and produced 775 seeds, of which $72(9 \%)$ germinated. A seedling tetraploid (accession 107.07) from a 2016 tetraploid parent (74.19) flowered, produced 152 seed, but none germinated (Table 7). Plant 75.15 is the only tree that has flowered each of the four years included in these data.

Amur maple in our plots have been relatively precocious and there were five, 22, and 22 triploids that flowered during 2018, 2019, and 2020, respectively. Most of these dropped undeveloped samaras prior to maturation but some did hold until the end of the season. Upon close observation, most appeared empty but all were stratified and sown. None have germinated to date.

\subsubsection{Trident Maple}

One trident maple flowered during 2016, from which we collected 793 seeds (Table 5). However, no seeds germinated. Neither the single triploid, nor any tetraploids flowered during 2017. During 2018, we collected seed from three diploids, one mixoploid, and one tetraploid. No germination occurred in field beds and germination in containers across ploidy levels was low and ranged from $5 \%$ to $8 \%$ for diploids, was $16 \%$ for the mixoploid, and was $10 \%$ for the tetraploid (Table 7). Seedlings from diploid branches were $85 \%$ diploid, $10 \%$ triploid and $5 \%$ tetraploid. Seedlings from mixoploid branches were all diploid, indicating these are likely chimeras with diploid LII histogenic layers. Surprisingly, the three seedlings from the tetraploid branch were all diploid, indicating that perhaps within this branch there are some nodes giving rise to tetraploid leaves and some remaining as chimeras with diploid LII histogenic layers (Table 8). During 2019, we collected seeds from four diploids and four mixoploids. Germination ranged from $0 \%$ to $4 \%$ for diploids and $0 \%$ to $2 \%$ for mixoploids (Table 7 ). Seedlings from diploid branches were $63 \%$ diploid, $13 \%$ triploid, $6 \%$ tetraploid and $19 \%$ pentaploid (Table 8 ). Seedlings from mixoploid branches were 59\% diploid, 23\% triploid and 18\% tetraploid (Table 8 ).

Table 8. Ploidy analysis using flow cytometry of seedlings resulting from open-pollination of field grown Acer buergerianum (trident maple). Seed were collected from 2016, 2018, and 2019 flowering season, respectively.

\begin{tabular}{|c|c|c|c|c|c|}
\hline Parent Location & Branch Ploidy & \multicolumn{4}{|c|}{ Plants at each Ploidy Level (\% of Tested) } \\
\hline \multicolumn{6}{|c|}{2016} \\
\hline & & $2 x$ & $3 x$ & $4 x$ & $5 x$ \\
\hline $72.15^{1}$ & $4 x$ & - & - & - & - \\
\hline \multicolumn{6}{|c|}{2018} \\
\hline 72.18 & $2 x$ & $9(82)$ & $2(18)$ & 0 & 0 \\
\hline 72.21 & $2 x$ & $8(89)$ & 0 & $1(11)$ & 0 \\
\hline 72.16 & $2 x+4 x$ & $3(100)$ & 0 & 0 & 0 \\
\hline 72.18 & $2 x+4 x$ & $3(100)$ & 0 & 0 & 0 \\
\hline 72.18 & $4 x$ & $3(100)$ & 0 & 0 & 0 \\
\hline \multicolumn{6}{|c|}{2019} \\
\hline 72.13 & $2 x$ & $2(100)$ & 0 & 0 & 0 \\
\hline 72.18 & $2 x$ & $1(100)$ & 0 & 0 & 0 \\
\hline 72.20 & $2 x$ & 0 & $1(25)$ & $1(25)$ & $2(50)$ \\
\hline 73.18 & $2 x$ & $8(89)$ & $1(11)$ & 0 & 0 \\
\hline 72.18 & $2 x+4 x$ & $11(100)$ & 0 & 0 & 0 \\
\hline 72.20 & $2 x+4 x$ & $2(22)$ & $4(44)$ & $3(33)$ & 0 \\
\hline 73.19 & $2 x+4 x$ & 0 & $1(50)$ & $1(50)$ & 0 \\
\hline
\end{tabular}

${ }^{1} 793$ seeds were collected and none germinated. 


\section{Discussion}

Norway and Amur maples are important nursery and landscape species that have declined in sales due to their invasiveness. Previous research has attempted to address this by identifying existing cultivars of Norway maple that have reduced fertility [22]. Conklin and Sellmer [22] observed low to moderate germination during their study even though many of the cultivars studied are known to be relatively weedy but conceded that even though recommended methods for overcoming dormancy were followed, there may have been confounding factors. We have observed delayed germination of some Norway maple genotypes that required longer cold stratification than commonly recommended for the species. Additional observations related to flowering and seed set resulted in the conclusion that some cultivars such as Crimson King, Globosum, Faasen's Black, and Rubrum had relatively low seed set and were safe alternatives for landscapes [23]. Our observations of several of these cultivars in Western Oregon, particularly for Crimson King, have found that they are not reduced in fertility. Conflicting observations from different climatic regions points toward an environmental factor in fertility. This idea of safety among existing Norway maple cultivars has been propagated by others through citation of the Conklin and Sellmer research and also refers to newer cultivars that were developed for use in eastern North America such as 'Medzam' (Medallion ${ }^{\mathrm{TM}}$ ) as "virtually-seedless" [24] but it is unclear on what basis that claim was made other than that of the nursery that introduced the cultivar. These assertions of reduced fertility without sufficient evidence may have an impact on future releases of sterile cultivars. Touting plants as sterile that have either not been properly evaluated or have not flowered may prevent any future exceptions to be made following bans and/or could jeopardize acceptance among the public, who may rightly view such cultivars with skepticism. Indeed, even when there is a scientific basis for a plant that "should" have reduced fertility (e.g., triploidy), testing is still required. For instance, among 13 populations of triploid pears, Phillips et al. [20] observed $0 \%$ to $33 \%$ fertility compared to a fertile diploid control, which illustrated a genetic factor related to fertility.

To provide sterile cultivars for growers and land managers that will not escape cultivation we first successfully induced tetraploids by treating the meristem of newly germinated seedlings. This technique has been widely used across diverse taxa including Hibiscus acetosella [25] and Rhododendron [26], whereas other research used in vitro treatment to develop tetraploids to maintain the phenotype of 'Crimson Sentry' [27]. We were not successful in developing tetraploids by treating vegetative meristems in situ and thus if future researchers wish to use cultivars to maintain superior phenotypes, it is recommended to follow a similar protocol to Lattier et al. [27], which focused on in vitro treatment. Similar to previous research, we observed varying percentage of tetraploids and cytochimeras both within and among species. We did not further investigate the resulting mixoploids to determine LI and LIII histogenic layers through stomatal measurements (LI) or observations related to adventitious roots (LIII) as performed on Hibiscus acetosella [25]; however, we did retain all mixoploids due to the potential that they may be more precocious to flower and would breed as tetraploids based on the ploidy of LII. Additionally, we confirmed one cytochimera of Amur maple to be an LII tetraploid based on pollen size. Utility of cytochimeras to breed as tetraploids has been illustrated in other taxa such as the bigeneric hybrid xChitalpa [28]. However, due to the relative number of tetraploids in the current study and the precocity of flowering among them, we have not relied heavily on them for breeding. Cytochimeras in our program continue to exhibit variable ploidy levels including some stabilizing as diploids, others as tetraploids, and some maintaining as chimeras. Among chimeras we have confirmed individual branches varying in ploidy level, which requires testing ploidy level each year during flowering. Annual confirmation of ploidy of plants from which we collect seed has become our standard practice to ensure efficiency through sowing only populations of seed that will yield high percentage of triploids.

Other researchers have used non-targeted mutagenesis to develop sterile forms of Amur maple and observed that several selections had not flowered or produced seed for several years [29]. While sterility or reduced fertility is a common result following mutagenesis using radiation (e.g., 'Meiguicheng' 
orange [30]), the authors conceded that the treatment may simply have resulted in the non-flowering plants having a longer than typical juvenility period. In order to have the greatest assurance that plants will not set seed is to observe flowering in many environments in the presence of fertile pollinizers over many years. We chose to use ploidy manipulation, as developing triploid cytotypes has been demonstrated to be a reliable means to achieve greatly reduced fertility in woody landscape plants such as Campsis [21], Hypericum [31], and Pyrus [20].

To our knowledge, these are the first confirmed reports of triploid forms of Amur, Norway, or trident maples developed to date. After attempting interploidy crosses using hand pollination we found that the process was inefficient and resulted in relatively few seedlings. We opted to interplant diploids and tetraploids to allow open-pollination. Prior to planting we were not certain of the pollination syndromes of any of the three species. There are five breeding systems in the genus Acer, several of which are highly complex and variably expressed temporally but can be summarized to range from including perfect flowers to dioecy during a single season [32]. Norway maple has been referred to as having perfect flowers [33] but this is a miscategorization, and even making careful observations can result in erroneous conclusions if based on a single period of time, as flowers can shift from perfect to male or female. We have made seasonal observations over the past several years but have not conducted observations on the frequency required to resolve sex expression these three species. However, we have confirmed the presence of perfect and male flowers in both Amur and Norway maples. Regardless of sex expression and/or pollination syndrome, the relatively high percentage of triploids derived from tetraploid plants suggests that there is a high rate of outcrossing among the maples studied.

Thus far we have observed triploids of Amur maple flowering for three seasons and have not recovered any seedlings, even though there are fertile pollinizers interplanted. All plants that flowered initially set samaras but all desiccated prior to maturation. Nevertheless, we collected, stratified, and sowed these seeds and observed no germination. It is premature to refer to these plants as sterile, but the findings suggest these plants may have reduced fertility to remove the ecological threat presented by the species-type. Triploids of Amur, Norway, and trident maples all have been propagated by stem cuttings for evaluation in multiple locations over multiple years.

\section{Conclusions}

Treating germinated seedlings of Amur, Norway, and trident maples with oryzalin was effective in developing tetraploids. Early flowering tetraploids were hand pollinated but this was found to be inefficient at developing large seed lots. Alternatively, interplanting diploids and tetraploids that were allowed to open-pollinate resulting in thousands of seeds and many triploids. Triploids have now been interplanted with fertile diploids as well as tetraploids for evaluation. We have recovered no seedlings from five, 22, and 22 trees that flowered during these respective years, suggesting triploids may be sterile but further evaluation over multiple years and environments is required. Furthermore, our methods described for inducing polyploids were not necessarily optimized and improvements could be made to more efficiently induce polyploids of these and additional species of maple.

Author Contributions: Conceptualization, R.N.C.; methodology, R.N.C. and T.C.H.; formal analysis, R.N.C.; investigation, R.N.C. and T.C.H.; data curation, R.N.C. and T.C.H.; writing-original draft preparation, R.N.C.; writing-review and editing, R.N.C. and T.C.H.; supervision, R.N.C. and T.C.H.; project administration, R.N.C.; funding acquisition, R.N.C. All authors have read and agreed to the published version of the manuscript.

Funding: This research was funded Oregon Department of Agriculture for partial funding of this research provided in cooperation between the Oregon Department of Agriculture (ODA) Nursery Research and Regulatory Advisory Committee and the Oregon Association of Nurseries (OAN) Research Committee. Financial support for this program is provided through a research assessment included as part of ODA's annual nursery license fee. Additional funding provided from the J. Frank Schmidt Family Charitable Foundation, Hatch Act funds, and the USDA Northwest Center for Nursery Crops Research.

Acknowledgments: We wish to thank Mara Friddle, Gwyn Alanko, Adigun McLeod, Andrew Baker, Jason Lattier, and Kim Shearer for their technical support. 
Conflicts of Interest: The authors declare no conflict of interest.

\section{References}

1. Census of Horticultural Specialties for 2014. Available online: https://www.agcensus.usda.gov/Publications/ 2012/Online_Resources/Census_of_Horticulture_Specialties/ (accessed on 1 April 2020).

2. Karnosky, D.F. Dutch elm disease: A review of the history, environmental implications, control, and research needs. Environ. Conserv. 1979, 6, 311-322. [CrossRef]

3. Herms, D.A.; McCullough, D.G. Emerald ash borer invasion of North America: History, biology, ecology, impacts, and management. Annu. Rev. Entomol. 2014, 59, 13-30. [CrossRef] [PubMed]

4. Pimentel, D.; Zuniga, R.; Morrison, D. Update on the environmental and economic costs associated with alien-invasive species in the United States. Ecol. Econ. 2005, 52, 273-288. [CrossRef]

5. The PLANTS Database. Available online: http://plants.usda.gov (accessed on 1 April 2020).

6. Nowak, D.J.; Rowntree, R.A. History and range of Norway maple. J. Arboric. 1990, 16, 291-296.

7. Vining, K.J.; Contreras, R.N.; Ranik, M.; Strauss, S.H. Genetic methods for mitigating invasiveness of woody ornamental plants: Research needs and opportunities. HortScience 2012, 47, 1210-1216. [CrossRef]

8. Miller, J.; Bradford, K. The regulatory bottleneck for biotech specialty crops. Nat. Biotechnol. 2010, 28, 1012-1014. [CrossRef]

9. Contreras, R.N. The struggle is real (but fun!): Long term plant breeding at a public university. Acta Hort. 2017, 1212, 223-224. [CrossRef]

10. Contreras, R.N.; Shearer, K. Genome size, ploidy, and base composition of wild and cultivated. Acer. J. Amer. Soc. Hort. Sci. 2018, 143, 470-485. [CrossRef]

11. Lattier, J.D.; Chen, H.; Contreras, R.N. Improved method for enzyme digestion of root tips for cytology. HortScience 2017, 52, 1029-1032. [CrossRef]

12. Kumar, A.; Gupta, N. Applications of triploids in agriculture. In Plant Biology and Biotechnology; Bahadur, B., Venkat Rajam, M., Sahijram, L., Krishnamurthy, K., Eds.; Springer: New Delhi, India, 2015; pp. 385-396.

13. Wilson, J.Y. Cytological investigation of triploid sterility. Nature 1962, 195, 1329-1330. [CrossRef]

14. Ramsey, J.; Schemske, D.W. Pathways, mechanisms, and rates of polyploid formation in flowering plants. Annu. Rev. Ecol. Syst. 1998, 29, 467-501. [CrossRef]

15. Simmonds, N.W. Megasporogenesis and female fertility in three edible triploid bananas. J. Genet. 1960, 57, 269-278. [CrossRef]

16. Kihara, H. Triploid watermelons. Proc. Amer. Soc. Hort. Sci. 1951, 58, 217-230.

17. Ji, W.; Li, Z.Q.; Zhou, Q.; Yao, W.K.; Wang, Y.J. Breeding new seedless grape by means of in vitro embryo rescue. Genet. Mol. Res. 2013, 12, 859-869. [CrossRef] [PubMed]

18. Lehrer, J.M.; Brand, M.H.; Lubell, J.D. Induction of tetraploidy in meristematically active seeds of Japanese barberry (Berberis thunbergii var. atropurpurea) through exposure to colchicine and oryzalin. Sci. Hort. 2008, $119,67-71$

19. Rounsaville, T.J.; Touchell, D.H.; Ranney, T.G. Fertility and reproductive pathways in diploid and triploid Miscanthus sinensis. HortScience 2011, 46, 1353-1357. [CrossRef]

20. Phillips, W.D.; Ranney, T.G.; Touchell, D.H.; Eaker, T.A. Fertility and reproductive pathways of triploid flowering pears (Pyrus sp.). HortScience 2016, 51, 968-971. [CrossRef]

21. Oates, K.M.; Ranney, T.G.; Touchell, D.H.; Viloria, Z. Campsis $\times$ tagliabuana 'Chastity': A highly infertile triploid trumpet vine. HortScience 2014, 49, 343-345. [CrossRef]

22. Conklin, J.R.; Sellmer, J.C. Germination and seed viability of Norway maple cultivars, hybrids, and species. HortTechnology 2009, 19, 120-126. [CrossRef]

23. Conklin, J.R.; Selmer, J.C. Flower and seed production of Norway maple cultivars. HortTechnology 2009, 19, 91-95. [CrossRef]

24. Llewellyn, J. ONnursery crops Blog. Research Shows: Some Norway Maple Cultivars are Not Invasive. Available online: https:/onnurserycrops.com/2016/07/07/research-shows-some-norway-maple-cultivars-arenot-invasive/ (accessed on 3 September 2020).

25. Contreras, R.N.; Ruter, J.M.; Hanna, W.W. An oryzalin-induced autoallooctoploid of Hibiscus acetosella Welw. ex Hiern. 'Panama Red' (Malvaceae). J. Am. Soc. Hort. Sci. 2009, 134, 553-559. [CrossRef] 
26. Jones, J.R.; Ranney, T.G.; Eaker, T.A. A novel method for inducing polyploidy in Rhododendron seedlings. J. Am. Rhododendr. Soc. 2008, 62, 130-135.

27. Lattier, J.D.; Touchell, D.H.; Ranney, T.G.; Smith, J. In Vitro regeneration and polyploid induction of Acer platanoides L. 'Crimson Sentry'. J. Environ. Hort. 2013, 31, 246-252.

28. Olsen, R.T.; Ranney, T.G.; Viloria, Z. Reproductive behavior of induced allotetraploid xChitalpa and in vitro embryo culture of polyploid progeny. J. Am. Soc. Hort. Sci. 2006, 131, 716-724. [CrossRef]

29. Smith, A.G.; Noyszewski, A.K. Mutagenesis breeding for seedless varieties of popular landscape plants. ActaHort. 2018, 1191, 43-51. [CrossRef]

30. Huang, J.H.; Wen, S.X.; Zhang, Y.F.; Zhong, Q.Z.; Yang, L.; Chen, L.S. Abnormal megagametogenesis results in seedlessness of a polyembryonic 'Meiguicheng' orange (Citrus sinensis) mutant created with gamma-rays. Sci. Hortic. 2017, 217, 73-83. [CrossRef]

31. Trueblood, C.; Ranney, T.G.; Lynch, N.; Neal, J.; Olsen, R. Evaluating fertility of triploid clones of Hypericum androsaemum L. for use as non-invasive landscape plants. HortScience 2010, 45, 1026-1028. [CrossRef]

32. Gleiser, G.; Verdú, M. Repeated evolution of dioecy from androdioecy in Acer. New Phytol. 2004, 165, 633-640. [CrossRef]

33. Dirr, M.A. Manual of Woody Landscape Plants: Their Identification, Ornamental Characteristics, Culture, Propagation, and Uses; Stipes: Champaign, IL, USA, 2009.

Publisher's Note: MDPI stays neutral with regard to jurisdictional claims in published maps and institutional affiliations.

(C) 2020 by the authors. Licensee MDPI, Basel, Switzerland. This article is an open access article distributed under the terms and conditions of the Creative Commons Attribution (CC BY) license (http://creativecommons.org/licenses/by/4.0/). 